\title{
Study of Fitness, Virulence, and Fungicide Sensitivity of Lambertella corni-maris Causing Yellow Rot on Apple
}

Achour Amiri, Aaron W. Hawkins, and Katie A. Mulvaney, Washington State University, Department of Plant Pathology, Tree Fruit Research and Extension Center, Wenatchee, WA 98801

\begin{abstract}
Very little is known about the biology, epidemiology, and best practices to manage Lambertella rot, a newly identified postharvest disease caused by Lambertella corni-maris on apples in the United States. In this study, we investigated the prevalence of $L$. corni-maris in 92 grower lots throughout Washington State in 2016, evaluated the effect of nutrient availability on $L$. corni-maris growth, and $L$. corni-maris sensitivity to $\mathrm{pH}$, osmotic stress, and fungicides in vitro. We assessed pathogen aggressiveness on major apple cultivars and the efficacy of pre- and postharvest fungicides to control L. corni-maris on detached fruit. L. corni-maris was widespread and was found in $40 \%$ of the growers lots surveyed at frequencies ranging from 2 to $40 \%$ of the total decay. The fungus grew faster on acidic media such as apple juice agar and V8 agar media and was able to grow equally at $\mathrm{pH}$ values ranging from 3 to 7 . L. corni-maris isolates showed relatively low sensitivity to osmotic stress and grew

evenly at $1 \mathrm{M} \mathrm{KCl}$. All nine apple cultivars tested were susceptible to L. corni-maris, but the disease severity was significantly higher on some cultivars such as Honeycrisp, Piñata, and Gala. The baseline sensitivity of $100 \mathrm{~L}$. corni-maris isolates was determined based on the effective concentration necessary to inhibit $50 \%$ mycelial growth $\left(\mathrm{EC}_{50}\right)$ for fludioxonil, boscalid, pyraclostrobin + SHAM, pyrimethanil, and thiabendazole. The respective mean $\mathrm{EC}_{50}$ values were $0.07,0.84,1.32,2.45$, and $3.68 \mu \mathrm{g} / \mathrm{ml}$. Fludioxonil and pyrimethanil applied at label rates were the only fungicides able to control $L$. corni-maris effectively on detached apple fruit. This study is a first step toward understanding the ecophysiological requirements for L. corni-maris to survive and cause decay on apple, assessing potential shifts in fungicide sensitivity, and enhancing Lambertella rot management. We suggest "yellow rot" as the new common name for Lambertella rot.
\end{abstract}

Pome fruit, i.e., apple and pear, are prone to postharvest diseases caused by more than 90 fungal species (Heald and Ruehle 1931; Snowdon 1990). Blue mold, gray mold, and bull's-eye rot caused by Penicillium sp., Botrytis cinerea, and Neofabraea sp., respectively, are the major postharvest diseases in many apple growing regions. Others, such as Sphaeropsis rot, speck rot, and mucor rot caused by Sphaeropsis pyriputrescens (Kim and Xiao 2008), Phacidiopycnis washingtonensis (Kim and Xiao 2006; Xiao et al. 2005), and Mucor piriformis (Michailides and Spotts 1990), respectively, appear less consistently than the three aforementioned ones. Penicillium sp. and M. piriformis infect fruit at harvest and mainly during storage (Amiri and Bompeix 2005; Michailides and Spotts 1990; Sanderson and Spotts 1995). Infections by other fungal species may be initiated in the orchard, remain latent, and develop slowly even at low temperatures $\left(-1\right.$ to $\left.4{ }^{\circ} \mathrm{C}\right)$, low $\mathrm{O}_{2}(0.7$ to $2 \%)$, and high $\mathrm{CO}_{2}(0.5$ to $3 \%)$ concentrations.

Lambertella corni-maris von Höhnel is a new fungal pathogen reported to cause postharvest Lambertella rot on apple in Washington State (Wiseman et al. 2015). The disease was found in $36 \%$ of packinghouses surveyed between 2003 and 2005 in central Washington at frequencies ranging from 1 to $3 \%$ of total decay (Wiseman et al. 2015). L. corni-maris was previously reported on mummified apples in Switzerland and pears in Germany (Harrison and El Helaly 1935). The fungus causes brown spongy lesions that may exhibit sporadic yellow-tan and thick mycelia. Under laboratory conditions, L. cornimaris has been reported to cause disease on other fruit crops such as pear, plum, quince, orange, and lemon (Harrison and El Helaly 1935). Interestingly, L. corni-maris exhibited a strong antagonistic in vitro activity against mycelium of $B$. cinerea and several other fungi, whereas the supernatant from liquid cultures inhibited spore

Corresponding author: Achour Amiri, Email: a.amiri@wsu.edu

*The $\boldsymbol{e}$-Xtra logo stands for "electronic extra" and indicates that one supplementary figure is available online.

Accepted for publication 7 November 2016

C 2017 The American Phytopathological Society germination of several fungi but not $B$. cinerea (Wood 1953). More recently, $L$. corni-maris was found to have allelopathic activity against the brown rot fungus Monilinia fructigena (Murakami et al. 2007). L. corni-maris produces the antibiotics lambertellos 1,2, and 3, which have been suggested as the main mechanism of action against M. fructigena (Hirose et al. 2014).

The rare studies on $L$. corni-maris mostly investigated its antagonistic activities and it was seldom considered as a plant pathogen. Besides causing decays on fruit and therefore additional loss to packers, the economic impacts can be important if the fungus is considered as a quarantine pathogen in many countries where apples are exported. The reasons behind its emergence as a postharvest pathogen on apple fruit are still unknown. Although Wiseman et al. (2015) suggested L. corni-maris to infect fruit through wounds caused at harvest and handling, very little is known about its etiology and epidemiology. Understanding the growth and reproduction requirements, fitness ability, pathogenicity, and sensitivity to fungicides will improve our knowledge about the eco-physiological requirements of the fungus and help in developing efficient management strategies.

Therefore, this study was conducted to (i) investigate the prevalence and distribution of $L$. corni-maris on apple in Washington State, (ii) evaluate the fitness ability of $L$. corni-maris under various environmental conditions, (iii) evaluate $L$. corni-maris virulence to major apple cultivars, and (iv) determine in vitro and in vivo sensitivity to five pre- and postharvest fungicides.

\section{Materials and Methods}

Prevalence of $L$. corni-maris during the 2015-16 season. A total of 32 packinghouses and 92 grower lots (orchards) from 10 counties representing major apple production areas in Washington State were surveyed for L. corni-maris from January to April of 2016 on fruit harvested from mid-August to November of 2015 (Fig. 1). Fifty decayed fruit originating from each orchard were randomly collected on the packing line, laid on clamshells to avoid contacts between fruit, and transferred to the laboratory for further disease characterization. Following a first visual symptom assessment, isolations were made from all decayed fruit. Fruit were half-split with an ethanolsterilized knife and then fully split by hand, and a small piece of the flesh taken at the margin of decayed and healthy tissue inside the fruit was transferred to the center of a potato dextrose agar 
(PDA) plate. Plates were incubated in the dark at $22^{\circ} \mathrm{C}$ for 6 days and a second characterization of L. corni-maris was conducted as described by Wiseman et al. (2015).

L. corni-maris isolates. One hundred (100) L. corni-maris isolates were used to evaluate fungicide sensitivity in vitro. Six, 39, 33, and 22 isolates were collected in 2003, 2004, 2005, and 2016 respectively, from decayed apples sampled from multiple Washington packinghouses. These isolates were never exposed to four of the five fungicides tested below. Thiabendazole and thiophanate-methyl had been used years before these isolates were collected. However, these two fungicides were not used in the years of survey. Three isolates were used to study fitness abilities (Tables 1 and 2) and four isolates were used to evaluate fungicide sensitivity on detached fruit. Isolates were stored as mycelial plugs in $40 \%$ glycerol at $-80^{\circ} \mathrm{C}$ and grown on PDA in continuous darkness for several weeks until apothecia were observed. Ascospores from mature apothecia were recovered in $1 \mathrm{ml}$ of sterile distilled water (SDW), plated onto PDA plates, and incubated at $20^{\circ} \mathrm{C}$ for 24 to $36 \mathrm{~h}$. Germinating single

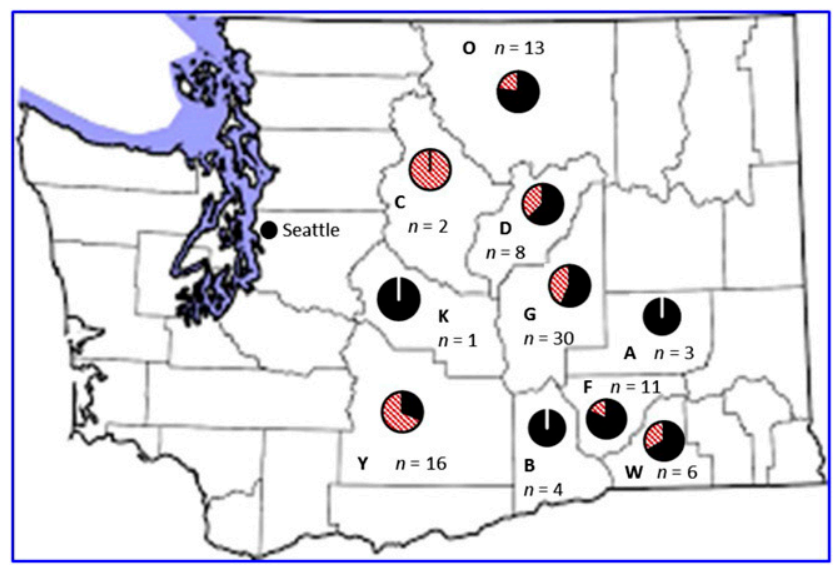

Fig. 1. Frequency distribution of Lambertella corni-maris in Washington apple packinghouses in the 2015-16 season. Black and dashed red portions correspond to grower lots without and with yellow rot, respectively. Bold letters A, B, C, D, F, G, $\mathrm{K}, \mathrm{O}, \mathrm{W}$, and $\mathrm{Y}$ indicate Adams, Benton, Chelan, Douglas, Franklin, Grant, Kittitas, Okanogan, Walla Walla, and Yakima counties, respectively. The letter $n$ indicates the number of grower lots survey for each county. spores observed using a stereoscope were transferred to fresh PDA plates. Isolates were stored at $-80^{\circ} \mathrm{C}$ as mycelial plugs in $40 \%$ glycerol.

Fitness abilities in vitro and virulence to different apple cultivars. Three different parameters including growth on different media, sensitivity to $\mathrm{pH}$, and osmotic stress were evaluated in vitro using three isolates LCM-2776, LCM-3441, and LCM-4050. Growth ability was evaluated on five different media, i.e., PDA, apple juice agar (AJA; $800 \mathrm{ml} \mathrm{H}_{2} \mathrm{O}, 200 \mathrm{ml}$ of fresh apple juice made from Red Delicious apples, $15 \mathrm{~g}$ agar), V8 agar (V8A; $800 \mathrm{ml} \mathrm{H}_{2} \mathrm{O}, 200 \mathrm{ml}$ low-sodium V8 juice [Campbell's, Camden, $\mathrm{NJ}$ ], $2 \mathrm{~g} \mathrm{CaCO}_{3}, 15 \mathrm{~g}$ agar), malt yeast extract agar (MYA; $5 \mathrm{~g}$ malt extract, $5 \mathrm{~g}$ yeast extract, $10 \mathrm{~g}$ dextrose, $15 \mathrm{~g}$ agar), and intermediate medium (IM) reported previously to mimic plant substrates (Amiri et al. 2014; Manteau et al. 2003). For each isolate, two 6-mm plugs taken from the edge of a 10-day-old colony were transferred upside down to a plate of each of the five aforementioned media. Plates were incubated for 7 days at $20^{\circ} \mathrm{C}$ in the dark or a $12-\mathrm{h}$ photoperiod before radial mycelial growth was measured. Four plates of each medium were used for each isolate and photoperiod and the experiment was conducted twice. The ability of the three isolates to grow at different $\mathrm{pH}$ levels was evaluated on PDA. The $\mathrm{pH}$ of the medium was modified to values ranging between 3 and 5 with different volumes of $2 \mathrm{M}$ citric acid buffer and to values ranging from 6 to 8 with a $2 \mathrm{M}$ Tris (hydroxymethyl) aminomethane buffer. The experiments were conducted and evaluated as described above for growth on different media except that plates were incubated in the dark and the growth was evaluated after 5 days incubation. Sensitivity to osmotic stress was evaluated on PDA amended with $0.25,0.5$, or $1.0 \mathrm{M} \mathrm{KCl}$ as described for the $\mathrm{pH}$ study but at two different temperatures, 5 and $20^{\circ} \mathrm{C}$. Mycelial growth was measured after 20 and 5 days incubation, respectively. For the $\mathrm{pH}$ and osmotic stress studies, four plates were used for each $\mathrm{pH}$ values or $\mathrm{KCl}$ concentration at each temperature and the trials were conducted twice.

The susceptibility to L. corni-maris of nine apple cultivars, i.e., Ambrosia, Braeburn, Cameo, Fuji, Gala, Granny Smith, Honeycrisp, Piñata, and Red Delicious, was evaluated on detached apple fruit. Organic fruit were washed in $0.8 \%$ sodium hypochlorite for $2 \mathrm{~min}$, rinsed abundantly with tap water, air-dried, and wounded twice near the stem end area. A 5-mm diameter mycelial plug taken from the edge of 7-day-old colony of isolate LCM-2776 was placed on each wound. To evaluate the ability of L. corni-maris to cause infections on unwounded fruit, four Fuji and Honeycrisp apples were inoculated by placing two mycelial plugs directly on the cuticle. Fruit

Table 1. Growth of Lambertella corni-maris isolates on different media under various photoperiod regimes

\begin{tabular}{|c|c|c|c|c|c|c|}
\hline \multicolumn{7}{|c|}{ Radial growth $(\mathrm{mm}) \pm \mathrm{SD}^{\mathrm{z}}$} \\
\hline \multirow[b]{2}{*}{ Medium } & \multicolumn{2}{|c|}{ LCM-2776 } & \multicolumn{2}{|c|}{ LCM-3441 } & \multicolumn{2}{|c|}{ LCM-4050 } \\
\hline & Dark & $12 \mathrm{~h}$ & Dark & $12 \mathrm{~h}$ & Dark & $12 \mathrm{~h}$ \\
\hline AJA & $36.6 \pm 2.4 \mathrm{a}$ & $33.1 \pm 1.6 \mathrm{a}$ & $31.9 \pm 3.1 \mathrm{a}$ & $33.1 \pm 3.6 \mathrm{a}$ & $32.3 \pm 2.4 \mathrm{a}$ & $34.0 \pm 3.5 \mathrm{a}$ \\
\hline V8 & $30.6 \pm 3.2 \mathrm{~b}$ & $29.4 \pm 2.5 \mathrm{~b}$ & $30.1 \pm 1.8 \mathrm{ab}$ & $27.8 \pm 1.3 \mathrm{bc}$ & $30.5 \pm 0.6 b$ & $30.3 \pm 2.0 \mathrm{bc}$ \\
\hline MYA & $31.3 \pm 1.4 \mathrm{~b}$ & $29.0 \pm 1.4 \mathrm{~b}$ & $28.1 \pm 3.7 b c$ & $28.5 \pm 4.4 b c$ & $30.2 \pm 2.1 \mathrm{~b}$ & $30.9 \pm 0.9 b$ \\
\hline IM & $26.8 \pm 2.1 \mathrm{c}$ & $27.8 \pm 1.0 \mathrm{bc}$ & $26.1 \pm 1.6 \mathrm{c}$ & $28.8 \pm 1.1 \mathrm{~b}$ & $30.1 \pm 1.0 \mathrm{~b}$ & $28.9 \pm 2.5 \mathrm{c}$ \\
\hline PDA & $27.3 \pm 2.1 \mathrm{c}$ & $26.5 \pm 3.7 \mathrm{c}$ & $27.4 \pm 3.4 \mathrm{c}$ & $26.1 \pm 3.2 \mathrm{c}$ & $26.8 \pm 4.0 \mathrm{c}$ & $26.8 \pm 1.4 \mathrm{~d}$ \\
\hline
\end{tabular}

${ }^{\mathrm{z}}$ Radial growth of L. corni-maris isolates after 7 days incubation at $22^{\circ} \mathrm{C}$ in continuous darkness or a $12 \mathrm{~h}$ photoperiod. Data are the means of 16 measurements from 8 replicate-plates across two experimental runs. Values, within each column, followed by different letters are significantly different based on the Student's $t$-test $(P=0.05)$.

Table 2. Effect of osmotic stress and temperature on growth of Lambertella corni-maris in vitro

\begin{tabular}{|c|c|c|c|c|c|c|}
\hline \multirow[b]{3}{*}{$\mathrm{KCl}$ concentration } & \multicolumn{6}{|c|}{ Radial growth $(\mathrm{mm}) \pm \mathrm{SD}^{\mathrm{z}}$} \\
\hline & \multicolumn{3}{|c|}{$5^{\circ} \mathrm{C}$} & \multicolumn{3}{|c|}{$22^{\circ} \mathrm{C}$} \\
\hline & LCM-2776 & LCM-3441 & LCM-4050 & LCM-2776 & LCM-3441 & LCM-4050 \\
\hline $0.25 \mathrm{M}$ & $17.3 \pm 2.2 \mathrm{a}$ & $14.2 \pm 2.0 \mathrm{a}$ & $15.4 \pm 1.7 \mathrm{a}$ & $29.5 \pm 3.1 \mathrm{a}$ & $25.6 \pm 3.8 \mathrm{a}$ & $26.5 \pm 3.5 \mathrm{a}$ \\
\hline $0.5 \mathrm{M}$ & $16.8 \pm 1.2 \mathrm{a}$ & $13.1 \pm 1.7 \mathrm{a}$ & $14.6 \pm 1.9 \mathrm{a}$ & $27.3 \pm 3.8 \mathrm{ab}$ & $24.4 \pm 1.7 \mathrm{a}$ & $23.4 \pm 3.5 b$ \\
\hline $1.0 \mathrm{M}$ & $7.5 \pm 0.8 b$ & $6.5 \pm 0.9 b$ & $5.8 \pm 0.6 \mathrm{~b}$ & $25.5 \pm 1.2 \mathrm{~b}$ & $21.4 \pm 1.5 \mathrm{~b}$ & $23.2 \pm 1.2 \mathrm{~b}$ \\
\hline
\end{tabular}

${ }^{\mathrm{z}}$ Radial growth of $L$. corni-maris isolates after 20 and 5 days incubation at 5 and $22^{\circ} \mathrm{C}$, respectively. Data are the means of 16 measurements from 8 replicate-plates across two experimental runs. Values, within each column, followed by different letters are significantly different based on the Student's $t$-test $(P=0.05)$. 
were placed in sealed boxes containing $200 \mathrm{ml}$ of sterile water and incubated at 1 or $20^{\circ} \mathrm{C}$ in continuous darkness. Disease incidence and lesion diameter were evaluated after 45 and 10 days incubation, respectively. Eight fruit were used for each cultivar/temperature combination and the trial was repeated twice.

Baseline fungicide sensitivity in vitro. A total of 100 L. corni-marris isolates collected and maintained as described above were evaluated for their sensitivity to five fungicides using a mycelial growth inhibition assay. Sensitivity was evaluated to formulated preharvest boscalid (Endura, BASF Corporation) and pyraclostrobin (Cabrio, BASF) and the postharvest thiabendazole (TBZ, Mertect340-F, Syngenta Crop Protection), pyrimethanil (Penbotec 400 SC, Janssen PMP, Beerse, Belgium), and fludioxonil (Scholar SC, Syngenta Crop Protection). The sensitivity to fludioxonil and boscalid was evaluated on PDA and a minimal medium (Hu et al. 2011), respectively, at final concentrations of $0.001,0.01,0.1$, and $1.0 \mu \mathrm{g} / \mathrm{ml}$, and on PDA for TBZ at final concentrations of $0.01,0.1,1.0$, and $10 \mu \mathrm{g} / \mathrm{ml}$, and pyraclostrobin at final concentrations of $0.005,0.05,0.5$, and $5.0 \mu \mathrm{g} / \mathrm{ml}$. Salicylhydroxamic acid (SHAM) was added to PDA at a final concentration of $100 \mu \mathrm{g} / \mathrm{ml}$ to test for pyraclostrobin. Sensitivity to pyrimethanil was evaluated on asparagine-agar (Hilber and Schüepp 1996) amended with $0.002,0.02,0.2$, and $2.0 \mu \mathrm{g} / \mathrm{ml}$ active ingredient. For each isolate, mycelial plugs (6-mm diameter), taken from the edge of an actively growing colony, were transferred upside down onto fungicide-amended and nonamended plates (two plugs/plate). Four plates were used for each fungicide concentration/isolate combination and the plates were incubated in continuous dark for 5 days at $20^{\circ} \mathrm{C}$. The diameter of each colony was measured in two perpendicular directions and the two values were averaged to calculate effective concentration for $50 \%$ inhibition $\left(\mathrm{EC}_{50}\right)$ values.

Efficacy of pre and postharvest fungicides for $L$. corni-maris control on detached fruit. Four isolates LCM-2876, LCM-2873, LCM-3852, and LCM-3872 were used to evaluate the efficacy of five fungicides on detached fruit. These isolates were selected because they exhibited different levels of sensitivity in vitro. Fruit were surface-sterilized and wounded as described above and dipped for $30 \mathrm{~s}$ in fungicide suspensions of formulated boscalid (Endura), pyraclostrobin (Cabrio), thiabendazole (Mertect340-F), pyrimethanil (Penbotec400 SC), and fludioxonil (Scholar SC) at label rates of $0.6 \mathrm{~g} / \mathrm{liter}, 0.72 \mathrm{~g} / \mathrm{liter}, 0.5 \mathrm{ml} / \mathrm{liter}, 2.5 \mathrm{ml} / \mathrm{liter}$, and $0.78 \mathrm{ml} /$ liter, respectively. Control fruit were dipped in sterile water. Fruit were incubated overnight at room temperature and inoculated with a 5-mm diameter mycelium plug placed upside down on each wound. The fungicides were applied preventively because our main objective is to evaluate the actual efficacy of the fungicides in relation to the sensitivity level of the isolates in vitro. Fruit were incubated as described above and disease incidence and lesion diameter were evaluated after 7 days. Six fruit were used for each treatment and the trial was conducted twice.

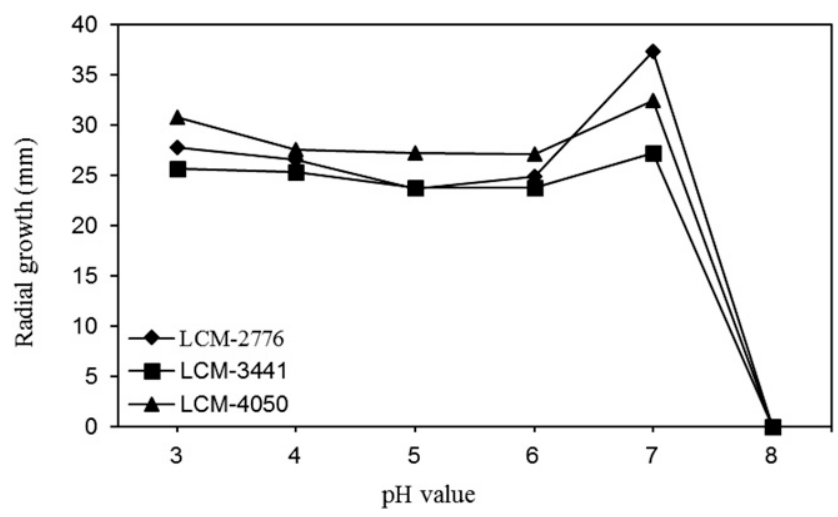

Fig 2. Effect of pH on mycelial growth of Lambertella corni-maris isolates after 5 days incubation at $22^{\circ} \mathrm{C}$ in continuous dark. Data point are means of 16 measurements across two experimental runs.
Statistical analysis. Data from the two replications were combined for statistical analysis after no significant difference was observed based on the Student's $t$-test. Logarithmically transformed fungicide concentrations and the probit values (Finney 1952) transformed from the respective percentage inhibition were used to calculate $\mathrm{EC}_{50}$ values. Disease severity relative to untreated control and disease incidence were arcsin transformed for ANOVA analysis and mean separation using Student's $t$-test. All statistical analyses were performed using JMP statistical software version 12.1.0 (SAS Institute Inc. Cary, NC)

\section{Results}

Prevalence of yellow rot in the 2015-16 season. Most decayed fruit identified to be caused by $L$. corni-maris showed strong yellow compact mycelium at late stages of disease development (Supplementary Fig. S1). Wiseman et al. (2015) described lesions caused by $L$. corni-maris on artificially inoculated fruit to show yellowtan mycelia. Therefore, we propose "yellow rot" as a common name for Lambertella rot. Yellow rot was widespread across Washington State and occurred in 37 of 92 grower lots (40.2\%) surveyed in 2016 (Fig. 1), accounting for $6.25 \%$ of the total decayed fruit. The frequency of grower lots showing yellow rot was the highest in Chelan County (100\%) followed by Yakima (68.8\%), Grant (43.3\%), and Douglas (37.5\%) counties (Fig. 1). Yellow rot was not detected in packinghouses from Adams and Kittitas counties in central Washington and Benton County in south Washington (Fig. 1). Yellow rot incidence ranged from 2.0 to $38.0 \%$ of decayed fruit per grower lot. Moreover, about $40 \%$ of surveyed grower lots had yellow rot incidence higher than 5\% (data not shown).

Fitness parameters and cultivar susceptibility. All isolates grew significantly $(P=0.0092)$ faster on apple juice agar compared with all other media, whereas PDA supported growth the least (Table 1). L. corni-maris isolates grew equally on V8 and malt extract, slightly faster compared with IM medium. Yellowish colonies were observed on all media for the first 4 days, then turned dark brown except on V8 agar, on which light white colonies were observed. Overall, the lighting conditions did not significantly $(P=0.6257)$ affect $L$. corni-maris growth. $L$. corni-maris isolates were moderately sensitive to osmotic stress as all isolates grew equally at 0.25 and $0.5 \mathrm{M} \mathrm{KCl}$ and was significantly reduced at $1 \mathrm{M} \mathrm{KCl}$ at $1^{\circ} \mathrm{C}$ (Table 2). All three L. corni-maris isolates grew equality a $\mathrm{pH}$ values ranging between 3 and 6 , whereas the growth increased slightly at $\mathrm{pH} 7$ but was completely inhibited at $\mathrm{pH} 8$ (Fig. 2). Growth decreased from about 28 to $32 \mathrm{~mm}$ at $\mathrm{pH} 3$ to $26 \mathrm{~mm}$ at $\mathrm{pH}$ values between 4 and 6 , and increased to 30 and $34 \mathrm{~mm}$ for LCM-4050 and LCM-2776, respectively, at pH 7 (Fig. 2).

Although the disease incidence was similar among all nine apple cultivars tested (data not shown), significant differences were observed in L. corni-maris severity among the cultivars. After 45 days of storage at $1^{\circ} \mathrm{C}$ in regular atmosphere, Red Delicious, Cameo, and Granny Smith had significantly lower L. corni-maris severity whereas the severity on Honeycrisp, Fuji, Gala, and Piñata was significantly higher (Fig. 3A). Similar trend was observed after 10 days storage at $20^{\circ} \mathrm{C}$ where Red Delicious, Granny Smith, and Ambrosia had significantly lower severity compared with Honeycrisp and Piñata (Fig. 3B). Interestingly, apples inoculated on nonwounded cuticle did not develop yellow rot.

During the survey conducted in 2016 in multiple packinghouses, yellow rot was observed on 10 different apple cultivars. However, incidence was higher on Fuji (10\%), Cripps Pink (6.4\%), Honeycrisp (6.1\%), and Piñata and Gala (5\%), whereas yellow rot incidence was low (2\%) on cultivars such as Breaburn, Red, and Golden Delicious (data not shown).

Fungicide sensitivity in vitro. The lowest mean $\mathrm{EC}_{50}$ value was registered for fludioxonil $(0.07 \mu \mathrm{g} / \mathrm{ml})$, for which values ranged from 0.02 to $0.14 \mu \mathrm{g} / \mathrm{ml}$, whereas the highest mean $\mathrm{EC}_{50}$ was observed for TBZ $(3.68 \mu \mathrm{g} / \mathrm{ml})$ with values ranging from 0.64 to $10.9 \mu \mathrm{g} / \mathrm{ml}$ (Table 3). The mean $\mathrm{EC}_{50}$ values for boscalid, pyraclostrobin, and pyrimethanil were $0.84,1.32$, and $2.45 \mu \mathrm{g} / \mathrm{ml}$, respectively. Variation factors were all bellow 100 except for pyrimethanil $(\mathrm{VF}=134)$. The 
frequency distribution of $\mathrm{EC}_{50}$ values fitted a unimodal curve with a normal distribution for fludioxonil and had a strong skew to the left compared with that of pyraclostrobin and pyrimethanil (Fig. 4).

Control of $L$. corni-maris with pre- and postharvest fungicides on detached fruit. Fludioxonil (Scholar) applied at label rate completely controlled $L$. corni-maris isolates regardless of their $\mathrm{EC}_{50}$ values $(0.07$ to $0.14 \mu \mathrm{g} / \mathrm{ml})$ on detached fruit after 10 days incubation at $20^{\circ} \mathrm{C}$ (Table 4). Pyrimethanil (Penbotec 400SC) provided a significantly greater efficacy compared with the other fungicides except fludioxonil and $L$. corni-maris severity was not significantly different from that of fludioxonil, i.e., for the isolate with an $\mathrm{EC}_{50}$ value of $13.5 \mu \mathrm{g} / \mathrm{ml}$. Although the disease incidence was numerically lower when pyraclostrobin was used at label rate compared with boscalid, significant differences were not observed between the two fungicides in incidence and severity, which were correlated to the sensitivity
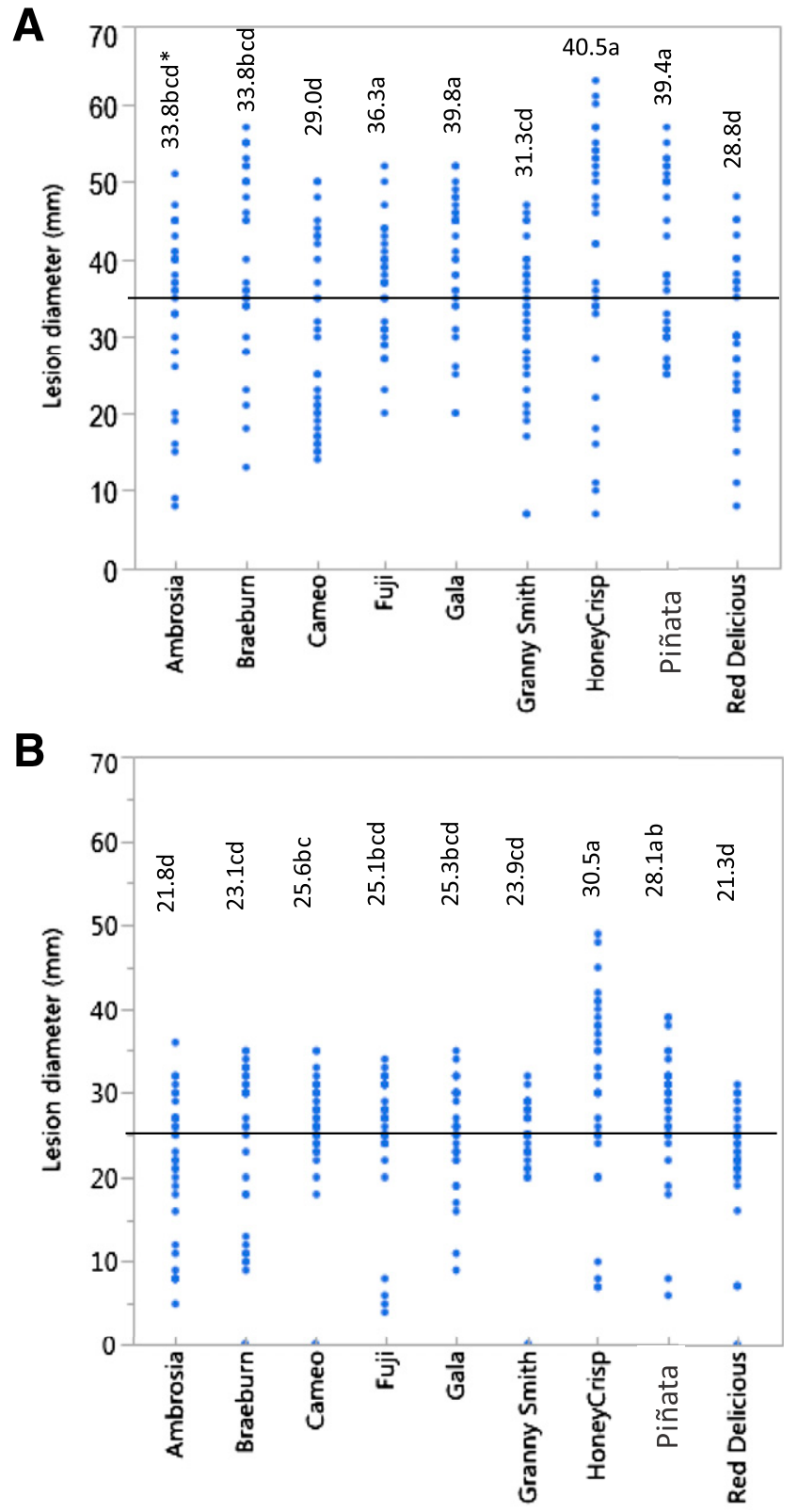

Cultivar

Fig. 3. Distribution and mean diameter of lesions caused by Lambertella corni-maris on several apple cultivars after 45 days of storage at $1^{\circ} \mathrm{C}(\mathbf{A})$ and 10 days of storage at $22^{\circ} \mathrm{C}$ (B). Points distributed vertically represent 16 specific measurements for each cultivar across two experimental runs and the mean diameter values are shown at the top-end distribution for each cultivar. Mean lesion diameter values followed by different letters are significantly different based on the Student's $t$-test $(P=0.05)$. levels of isolates. Thiabendazole failed to control $L$. corni-maris and resulted in a higher severity compared with the untreated control fruit (Table 4).

\section{Discussion}

Yellow rot caused by L. corni-maris continues to cause postharvest losses in multiple packinghouses in Washington State. Hence, $40 \%$ of grower lots surveyed in the 2015-16 season had yellow rot incidences higher than 5\%. Even though the overall disease incidence may seem low to cause significant economic losses for apple fruit packers, other fungal pathogens, such as Phacidiopycnis washingtonensis (Xiao et al. 2005) and Sphaeropsis pyriputrescens (Xiao and Rogers 2004), reported to cause postharvest decay at relatively similar frequencies in the Pacific Northwest, resulted in nearly $\$ 20$ million losses a year due to rejection of fruit lots from many countries where these pathogens are considered quarantine pathogens. It is still unclear whether the presence of $L$. corni-maris in many packinghouses, nearly 10 years after its first characterization in 2005 , only reported recently (Wiseman et al. 2015), is due to a change in climatic conditions that affected the region or by a shift in pre- and postharvest practices undergone by the apple fruit industry in the recent years, including the introduction of new cultivars and reliance on new fungicides.

Nutrients, water, space, and oxygen are among various conditions required by fungi to grow and reproduce. Knowing that a fungus often has to compete with other fungi and microorganisms for its survival, it becomes important to understand the specific needs of each species and conditions that may favor infections. In a recent study, growth and germination of L. corni-maris was optimal at $20^{\circ} \mathrm{C}$, whereas its growth was reduced at $0^{\circ} \mathrm{C}$ and completely inhibited at temperatures $\geq 30^{\circ} \mathrm{C}$ (Wiseman et al. 2015). Findings from our investigation suggest that $L$. corni-maris can grow under a wide range of conditions including some that may be less favorable for other fungal species. Thus, L. corni-maris grew slightly faster under more acidic conditions ( $\mathrm{pH} 3$ ) compared with $\mathrm{pH}$ values ranging from 4 to 6 and grew significantly faster on apple juice agar (AJA) compared with other media, such as PDA, commonly used to grow fungi in vitro. Harrison and El-Helaly (1935) reported that L. corni-maris was able to grow over a wide range of $\mathrm{pH}$ ranging from 1.6 to 8.3 on different media and that growth was optimal at $\mathrm{pH} 4.4$. Herein, L. corni-maris was completely inhibited at $\mathrm{pH} 8$ and grew optimally at $\mathrm{pH}$ 7. Although environmental $\mathrm{H}^{+}$concentration $(\mathrm{pH})$ impact on fungi has been suggested to be minimized by the buffering system in hyphae and conidia (Dix and Webster 1995), extreme pH conditions may influence enzymatic activity of fungi (Aleandri et al. 2007; Enokibara et al. 1993). Thus, L. corni-maris was reported to be very active in excreting oxidizing enzymes and pectinase (Harrison and El-Helaly 1935) and antibiotics known as lambertellin or lambertellols 1, 2, and 3 (Armstrong and Turner 1965; Murakami et al. 2004). Very interestingly, lambertellols were produced by L. corni-maris at substantial amounts under acidic conditions ( $\mathrm{pH} 3$ ) but very scarcely at pH 6.3 (Murakami et al. 2007). Consequently, antagonistic activity of $L$. corni-maris was only observed at low $\mathrm{pH}$ against a range of other fungal pathogens (Murakami et al.

Table 3. Effective concentrations to inhibit 50\% mycelial growth of Lambertella corni-maris by five pre- and postharvest fungicides

\begin{tabular}{lccr}
\hline & \multicolumn{2}{c}{$\mathbf{E C}_{\mathbf{5 0}}(\boldsymbol{\mu g} / \mathbf{m l})^{\mathbf{y}}$} & \\
\cline { 2 - 3 } Fungicide & Mean & Range & CV $^{\mathbf{z}}$ \\
\hline Fludioxonil & 0.07 & $0.02-0.14$ & 7 \\
Boscalid & 0.84 & $0.11-2.55$ & 23 \\
Pyraclostrobin & 1.32 & $0.10-9.91$ & 99 \\
Pyrimethanil & 2.45 & $0.10-13.4$ & 134 \\
Thiabendazole & 3.68 & $0.64-10.9$ & 17 \\
\hline
\end{tabular}

${ }^{\mathrm{y}}$ Mean and range of effective concentrations to inhibit 50\% mycelial growth $\left(\mathrm{EC}_{50}\right)$ calculated using $100 \mathrm{~L}$. corni-maris isolates from multiple packinghouses in Washington between 2003 and 2005.

${ }^{\mathrm{z}}$ Coefficient of variation was calculated by dividing the highest $\mathrm{EC}_{50}$ value by the lowest $\mathrm{EC}_{50}$ value for each fungicide within the population. 
2007; Wood 1953). In addition to its ability to grow in acidic environments, L. corni-maris was not susceptible to osmotic stress as it grew at $1 \mathrm{M} \mathrm{KCl}$ even at low temperatures. While water availability may not be an issue in postharvest storage rooms where ambient humidity is usually high enough for fungi to thrive, apple growing regions in the $\mathrm{Pa}$ cific Northwest are subaridic and can be unfavorable for many fungal pathogens in such orchards. However, it may be possible that L. cornimaris can survive effectively in relatively dry conditions and continue to cause latent infections that result in postharvest diseases.

Mean $\mathrm{EC}_{50}$ values for fludioxonil in vitro correlated well with in vivo efficacy of the fungicide applied at label rate. A variation factor (7) for this fungicide was the lowest among all fungicides tested, which may reflect a low intrinsic variability in sensitivity to fludioxonil among L. corni-maris isolates. The latter was the only postharvest fungicide applied at low label rate able to completely control L. corni-maris isolates, i.e., those with $\mathrm{EC}_{50}$ values as high as $0.14 \mu \mathrm{g} / \mathrm{ml}$. Correlation between in vitro $\mathrm{EC}_{50}$ values for pyrimethanil and in vivo efficacy were not always high since this fungicide had one of the highest mean $\mathrm{EC}_{50}(2.45 \mu \mathrm{g} / \mathrm{ml})$ in vitro. However, pyrimethanil applied at medium label rate successfully controlled L. corni-maris isolates, i.e., those with an $\mathrm{EC}_{50}$ value as high as $13 \mu \mathrm{g} / \mathrm{ml}$. Although not tested in this study, the higher label rate of pyrimethanil (Penbotec) should fully control isolates with high $\mathrm{EC}_{50}$ values equivalent to the ones found in this study. The wide range of $\mathrm{EC}_{50}$ values for pyrimethanil, seen in this study, may denote a wider inherent variability in sensitivity to this fungicide and potentially a higher risk, compared with fludioxonil, to shift toward reduced sensitivity. The two preharvest fungicides, pyraclostrobin and boscalid, are premixed as Pristine, which is widely used by apple growers as a preharvest fungicide. The two fungicides applied separately provided a moderate efficacy only against $L$. corni-maris isolates regardless of their $\mathrm{EC}_{50}$ value.
Further studies are needed to determine when apples are infected by L. corni-maris; however, our findings indicate that Pristine will not protect the fruit from infections in the orchard. Therefore, screening additional preharvest fungicides used in apple orchards would help identify most effective fungicide for yellow rot management if proven that fruit

Table 4. Efficacy of five pre and postharvest fungicides against Lambertella corni-maris isolates with different fungicide sensitivity levels on detached apple fruit

\begin{tabular}{lccrr}
\hline Fungicide $^{\mathbf{y}}$ & Isolate & EC $_{\mathbf{5 0}}(\boldsymbol{\mu} \mathbf{g} / \mathbf{m l})$ & Incidence $^{\mathbf{z}}$ & Severity $^{\mathbf{z}}$ \\
\hline Fludioxonil & LCM-2876 & 0.07 & $0.0 \mathrm{a}$ & $0.0 \mathrm{a}$ \\
& LCM-2873 & 0.14 & $0.0 \mathrm{a}$ & $0.0 \mathrm{a}$ \\
Pyrimethanil & LCM-2876 & 3.18 & $6.3 \mathrm{~b}$ & $6.4 \mathrm{a}$ \\
& LCM-3852 & 13.45 & $21.2 \mathrm{a}$ & $7.3 \mathrm{a}$ \\
Pyraclostrobin & LCM-2876 & 0.76 & $46.2 \mathrm{~b}$ & $50.2 \mathrm{~b}$ \\
& LCM-2887 & 9.91 & $68.8 \mathrm{a}$ & $87.5 \mathrm{a}$ \\
Boscalid & LCM-2876 & 0.66 & $46.3 \mathrm{~b}$ & $59.7 \mathrm{a}$ \\
& LCM-2873 & 2.55 & $68.8 \mathrm{a}$ & $69.9 \mathrm{a}$ \\
Thiabendazole & LCM-2876 & 1.74 & $100.0 \mathrm{a}$ & $120.5 \mathrm{a}$ \\
& LCM-3872 & 10.91 & $100.0 \mathrm{a}$ & 121.2 \\
\hline
\end{tabular}

${ }^{y}$ Fludioxonil, pyrimethanil, pyraclostrobin, boscalid, and thiabendazole were applied preventively as formulated Scholar_SC, Penbotec, Cabrio, Endura, and Mertect, respectively, at label rates. Treated fruit were incubated overnight at room temperature before inoculation.

${ }^{\mathrm{z}}$ Disease incidence was calculated based on the number of artificially inoculated wounds showing yellow rot infection whereas severity was calculated as the reduction in lesion diameter on fungicide-treated fruit relative to the control after 7 days incubation at $20^{\circ} \mathrm{C}$. Values, within each column and for each fungicide, followed by different letters are significantly different based on the Student's $t$-test $(P=0.05)$.
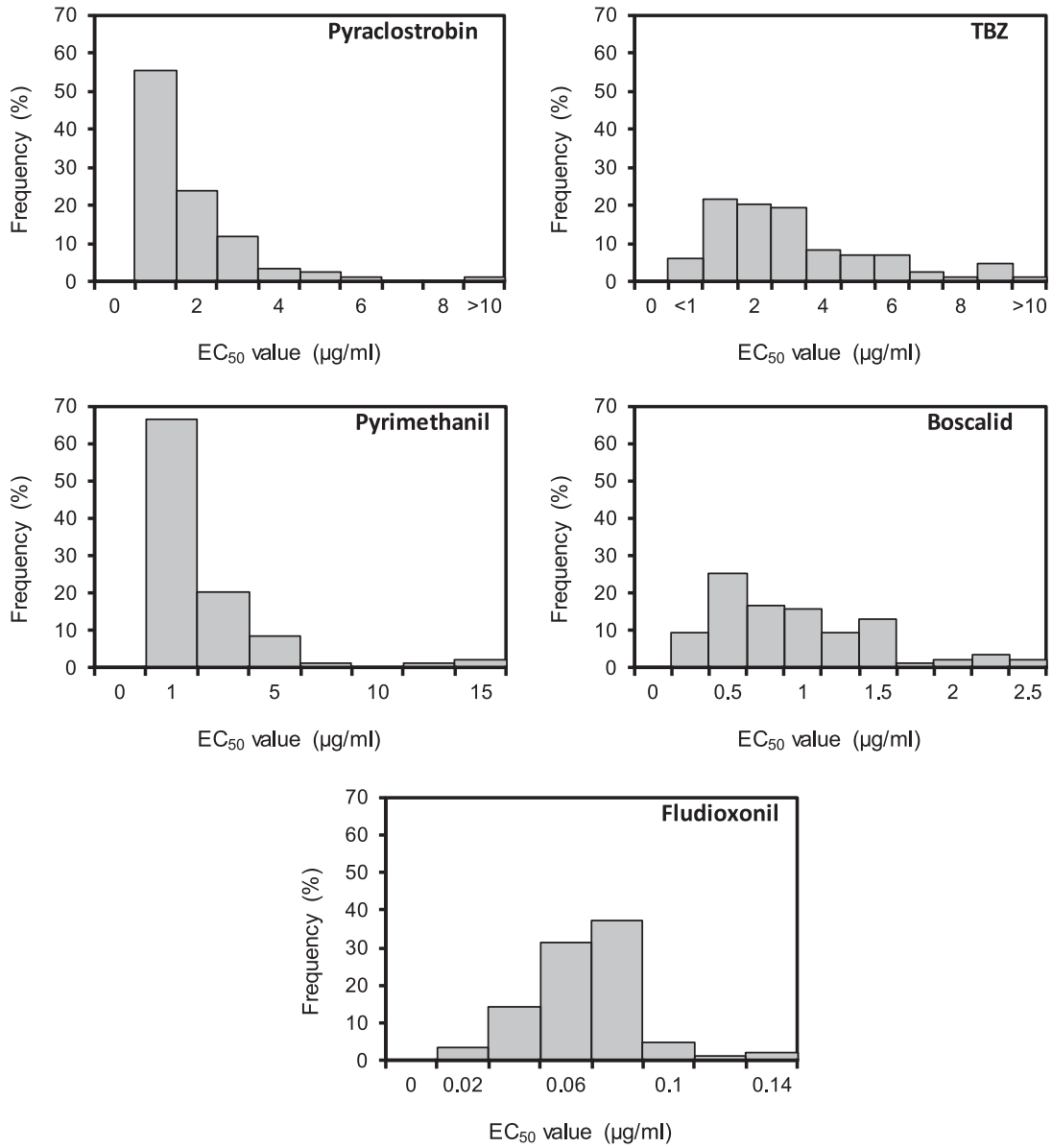

Fig. 4. Frequency distribution of $\mathrm{EC}_{50}$ values $(\mu \mathrm{g} / \mathrm{ml})$ for pyraclostrobin, thiabendazole pyrimethanil, boscalid, and fludioxonil of a Lambertella corni-maris baseline population $(n=100)$ from multiple packinghouses in Washington. 
infections occur preharvest. The postharvest fungicide TBZ had the highest mean $\mathrm{EC}_{50}$ value in vitro and completely failed to control L. corni-maris isolates in vivo regardless of their $\mathrm{EC}_{50}$ value. Similarly, thiophanate-methyl (Topsin-M) used as a preharvest fungicide in apple orchards will not, most likely, protect apples form L. corni-maris infections. Presently, applications of fludioxonil or pyrimethanil at harvest would provide appropriate control of yellow rot.

The ability of L. corni-marris to cause disease on multiple fruit and vegetables has been reported previously (Harrison and El Helaly 1935). However, its etiology and epidemiology in apple orchards is completely unknown. Wiseman et al. (2015) suggested that L. corni-maris infect the fruit through wounds, which implicates that the infections should occur at harvest when most wounds are caused on fruit. We present clear evidence that $L$. corni-maris requires a wound to infect apples. However, we cannot rule out other ways of pathogen penetration into fruit in the orchard. Whether $L$. cornimaris overwinters on apple trees between seasons or if there are alternative hosts that would be potential sources of $L$. corni-maris inoculum is still unknown. Recently, crabapple fruit and rose hips were found to be susceptible to L. corni-maris when wounded and inoculated artificially (Wiseman et al. 2016). Manchurian crabapple trees are common pollinizers in apple orchards and have been shown to be susceptible to other pathogens such as $P$. washingtonensis and S. pyriputrescens and suggested to be the main source of inoculum of these two pathogens (Xiao et al. 2009, 2014). Rose hip shrubs can be found around some orchards but not necessarily everywhere where apples are grown. Our present study indicates that L. cornimaris is present in all apple growing regions in the state and some surveyed locations, positive to L. corni-maris, did not have rose hips or other potential hosts in the vicinity. Further investigation is needed to assess the role of crabapple, and potentially, apple trees themselves as inoculum sources, as well as the infection timings to improve yellow rot management. The pathogen-pathogen interactions between L. corni-maris and other apple pathogens is also worth of future investigation to assess potential decay suppression by $L$. corni-maris. Indeed, the later produces antibiotics known as lambertellos shown to be antagonistic to several pathogens such as $B$. cinerea and M. fructigena (Hirose et al. 2014; Murakami et al. 2007; Wood 1953). It would be interesting to find some $L$. corni-maris isolates nonvirulent on apple that could be potentially used as biocontrol agents.

\section{Acknowledgments}

This work was supported in part by the Washington Tree Fruit Research Commission. PPNS \# 0729, Department of Plant Pathology, College of Agricultural, Human, and Natural Resource Sciences, Agricultural Research Center, Hatch Project No. WNP0555, Washington State University, Pullman, WA 99164-6430, USA.

\section{Literature Cited}

Aleandri, M. P., Magro, P., and Chilosi, G. 2007. Modulation of host pH during the wheat-Fusarium culmorum interaction and its influence on the production and activity of pectolytic enzymes. Plant Pathol. 56:517-525.

Amiri, A., and Bompeix, G. 2005. Diversity and population dynamics of Penicillium spp. on apple in pre- and postharvest environments: consequences for decay development. Plant Pathol. 54:74-81.

Amiri, A., Heath, S. M., and Peres, N. A. 2014. Resistance to fluopyram, fluxapyroxad, and penthiopyrad in Botrytis cinerea from strawberry. Plant Dis. 98:532-539.
Armstrong, J. J., and Turner, W. B. 1965. The structure of lambertellin. J. Chem. Soc. 1965:5927-5930.

Dix, N. J., and Webster, J. 1995. Pages 388-390 in: Fungal Ecology. Chapman \& Hall, London.

Enokibara, S., Suzuki, A., Kashiwagi, M., Mori, N., and Kimamoto, Y. 1993 Diversity of $\mathrm{pH}$ spectra of cellulotic enzymes in basidiomycetes. T. Mycol. Soc. JPN. 34:221-228.

Finney, D. J. 1952. Probit Analysis. Cambrige University Press, Cambridge, England.

Harrison, T. H., and El Helaly, A. F. 1935. On Lambertella corni-maris von Höhnel, a brown-spored parasitic discomycete. Trans. Br. Mycol. Soc. 19: 199-214.

Heald, F. D., and Ruehle, G. D. 1931. The rots of Washington apples in cold storage. Ext. Bull. No. 253. State College of Washington, Pullman.

Hilber, U. W., and Schüepp, H. 1996. A reliable method for testing the sensitivity of Botryotinia fuckeliana to anilinopyrimidines in vitro. Pestic. Sci. 47: 241-247.

Hirose, A., Kudo, S., Mukarami, T., Tanaka, K., Harada, Y., and Hashimoto, M. 2014. Lambertellin system, the mechanism of fungal replacement of Monilinia fructigena with Lambertella corni-maris without competitive inhibition on agar media. Bioorg. Med. Chem. 22:2489-2495.

Hu, M. J., Luo, C. X., Grabke, A., and Schnabel, G. 2011. Selection of a suitable medium to determine sensitivity of Monilinia fructicola mycelium to SDHI fungicides. J. Phytopathol. 159:616-620.

Kim, Y. K., and Xiao, C. L. 2006. A postharvest fruit rot in apple caused by Phacidiopycnis washingtonensis. Plant Dis. 90:1376-1381.

Kim, Y. K., and Xiao, C. L. 2008. Distribution and incidence of Sphaeropsis rot in apple in Washington State. Plant Dis. 92:940-946.

Manteau, S., Abouna, S., Lambert, B., and Legendre, L. 2003. Differential regulation by ambient $\mathrm{pH}$ of putative virulence factor secretion by the phytopathogenic fungus Botrytis cinerea. FEMS Microbiol. Ecol. 43:359-366.

Michailides, T. J., and Spotts, R. A. 1990. Postharvest diseases of pome and stone fruit caused by Mucor piriformis in the Pacific Northwest and California. Plant Dis. 74:537-543.

Murakami, T., Morikawa, Y., Hashimoto, M., Okuno, T., and Harada, Y. 2004 Lambertellos A and B, novel 3,4-dihydronaphthalen-1(2H)-ones with spirobutenolide produced by Lambertella sp. 1346. Org. Lett. 6:157-160.

Murakami, T., Takada, N., Harada, Y., Okuno, T., and Hashimoto, M. 2007. Stimulation of the biosynthesis of the antibiotics lambertellols by the mycoparasitic fungus Lambertella corni-maris under the acidic conditions produced by its host fungus in vitro. Biosci. Biotechnol. Biochem. 71:1230-1235.

Sanderson, P. G., and Spotts, R. A. 1995. Postharvest decay of winter pear and apple fruit caused by species of Penicillium. Phytopathology 85:103-110.

Snowdon, A. L. 1990. A Colour Atlas of Post-harvest Diseases and Disorders of Fruit and Vegetables: General Introduction and Fruits. Wolf Scientific Ltd., Taylor and Francis Ed., London.

Wiseman, M. S., Dugan, F. M., Kim, Y. K., and Xiao, C. L. 2015. A postharvest rot of apple caused by Lambertella corni-maris in Washington. Plant Dis. 99: 201-206.

Wiseman, M. S., Dugan, F. M., and Xiao, C. L. 2016. Potential hosts for Lambertella corni-maris and Phacidium lacerum within the family of Rosaceae. Plant Health Prog. 17:128-129.

Wood, S. 1953. The antagonism of Lambertella cornimaris to fungi and bacteria Trans. Br. Mycol. Soc. 36:109-110.

Xiao, C. L., Kim, Y. K., and Boal, R. J. 2009. A new canker disease of crabapple tree caused by Phacidiopycnis washingtonensis in Washington State. Plant Health Progress. Online publication. doi:10.1094/PHP-2009-0612-01-BR.

Xiao, C. L., Kim, Y. K., and Boal, R. J. 2014. Sources and availability of inoculum and seasonal survival of Sphaeropsis pyriputrescens in apple orchards. Plant Dis. 98:1043-1049.

Xiao, C. L., and Rogers, J. D. 2004. A postharvest fruit rot in d'Anjou pears caused by Sphaeropsis pyriputrescens sp. nov. Plant Dis. 88:114-118.

Xiao, C. L., Rogers, J. D., Kim, Y. K., and Liu, K. 2005. Phacidiopycnis washingtonensis-a new species associated with pome fruits from Washington State. Mycologia 97:464-473. 